\title{
Uma dimensão avaliativa do Fundef: a desigualdade regional
}

\section{An evaluative dimension of Fundef: regional inequality}

\author{
Romualdo Portela de Oliveira*
}

\begin{abstract}
RESUMO
O objetivo deste texto é discutir a desigualdade nacional em educação, tomando como referência o papel da esfera federal no financiamento da educação e de sua possível ação com vistas a diminuir as desigualdades intrafederativas. Toma-se como objeto de reflexão o Fundo de Manutenção e Desenvolvimento do Ensino Fundamental e de Valorização do Magistério - Fundef, de modo que na análise aqui desenvolvida também há uma dimensão de avaliação dessa iniciativa de política pública.

Palavras-chave: Fundef, financiamento da educação, políticas educacionais.
\end{abstract}

\begin{abstract}
The objective of this text is to discuss the national inequality on education having as reference the role of federal sphere in Education Financing and its intervention possibilities in order to reduce inequalities between the Brazilian states. Fundef - Fund of Maintenance and Development of the Fundamental Teaching and of Valorization of the Teaching is taken, here, as the reflection object, then, in this analysis there is also an evaluation dimension of that initiative of public politics.

Key-words: Fundef, financing of the education, education politics.

* Professor Doutor da Faculdade de Educação da Universidade de São Paulo (FE-
\end{abstract} USP).<romualdo@usp.br> 
A organização federativa do Estado nacional não se destina a enfrentar a questão da desigualdade, mas a da diversidade (ALMEIDA, 1996). Entretanto, ao pensarmos a educação enquanto um direito social é necessário problematizarmos a tensão existente entre a organização federativa, a igualdade de todos perante a lei e os direitos universais, retórica e recorrentemente proclamados e absolutamente distantes das práticas e das políticas públicas. Ao se propugnar por uma política descentralizadora e autonomista, tanto dos sistemas quanto das escolas, enfatiza-se a possibilidade de mais democracia nos processos de decisão, ao mesmo tempo em que se secundariza a preocupação com a questão da igualdade. Entretanto, a idéia de justiça subjacente ao imaginário liberal, particularmente quando se relaciona aos direitos sociais, é indissociável da igualdade de todos perante a lei. No caso dos direitos sociais, tal tensão se exacerba.

Ao confrontarmos a retórica democrática liberal com a realidade das propostas de políticas públicas nela ancoradas, verifica-se em que medida tais políticas rompem com os ciclos viciosos de iniciativas crescentemente desequalizadoras e amplificadoras da desigualdade. É essa dimensão avaliativa das políticas públicas que adquire centralidade no debate das políticas educacionais contemporâneas, pois, pelo menos em princípio, as políticas públicas deveriam se destinar a reduzir as desigualdades inerentes à sociedade capitalista. (MARSHALL, 1967)

O objetivo deste texto é discutir a desigualdade nacional em educação, tomando como referência o papel da esfera federal no financiamento da educação e de sua possível ação com vistas a diminuir as desigualdades intrafederativas. Toma-se como objeto de reflexão o Fundo de Manutenção e Desenvolvimento do Ensino Fundamental e de Valorização do Magistério - Fundef, de modo que na análise aqui desenvolvida também surja uma dimensão de avaliação dessa particular iniciativa de política pública.

\section{Federalismo, desigualdade e direitos}

Segundo William Anderson, no Dicionário de Ciências Sociais da Fundação Getúlio Vargas, 
...federalismo é o sistema político (e os princípios fundamentais desse sistema) que a) defende e estabelece um governo central para todo o país e determinados governos regionais autônomos (estados, províncias, länder, cantões) para as demais unidades territoriais; b) distribui os poderes e funções de governo entre os governo central e regionais; c) atribui às unidades regionais um conjunto de direitos e deveres; d) autoriza os governos de ambos os níveis a legislar, tributar e agir diretamente sobre o povo; e, e) fornece vários mecanismos e procedimentos para a resolução dos conflitos e disputas entre os governos central e regionais, bem como entre duas ou mais unidades regionais. (DICIONÁRIO DE CIÊNCIAS SOCIAIS, 1987, p. 471)

Esta sobreposição de governos, parcialmente autônomos, se expressa em toda a sua agudeza no que concerne à questão fiscal nas políticas sociais e em sua ação na distribuição de renda. Se há apenas um governo, a possibilidade deste desempenhar um papel redistributivo é inconteste. Se há governos autônomos, mesmo que dentro de limites, o quanto de poder cabe ao governo central e aos regionais é uma questão em permanente disputa. Da mesma forma, também, o quanto o governo central será redistributivo.

No outro pólo do processo, o dos direitos, a máxima da igualdade de todos perante a lei, aplicada aos direitos sociais, pressupõe um Estado redistributivo, caso contrário os indivíduos estariam sujeitos à ação autônoma do mercado, inerentemente desequalizador e a porções do Estado nacional com diversa capacidade de ação. Dessa forma, estabelece-se uma tensão entre a forma federativa, a universalidade e a igualdade de acesso aos direitos por parte dos cidadãos.

A atual discussão sobre a reforma tributária é uma expressão clara dessa tensão. Aos estados mais ricos interessa um menor poder arrecadador do poder central, enquanto que aos mais pobres interessa um papel maior do poder central no aspecto arrecadatório, de forma que tal aumento possa ser redistribuído segundo a lógica da redução das desigualdades.

Essa tensão entre centralização e descentralização não é inerente apenas ao regime federativo, entretanto neste ela se torna crucial.

O caso brasileiro é particularmente complicado pois, com a Constituição de 1988, os municípios tornaram-se entes federativos, constituindo um terceiro nível da federação. Os demais regimes federativos existentes no mundo restringem-se a dois níveis, o governo central e as províncias e/ ou estados. Isso faz com que a federação brasileira seja sui generis, apesar 
de ainda não se vislumbrar, em termos práticos, a possibilidade e a natureza da autonomia destes novos membros da federação. Essa peculiaridade pode ter impacto significativo na educação, pois assistimos a uma crescente responsabilização do município para com o atendimento do ensino fundamental. Nesse contexto, refletir sobre a temática da desigualdade regional pode ser fundamental para localizar os entraves existentes na sociedade brasileira à generalização da educação de qualidade para todos.

\section{Os diferenciais de acesso}

Uma das mais marcantes características da educação brasileira é a profunda desigualdade regional, gerada desde os primórdios da organização do Estado nacional. Sem ser este o objetivo deste trabalho, retomar as complexas condições políticas e econômicas que deram origem a um envolvimento desigual das diferentes esferas do poder público com o atendimento das necessidades educacionais da população, constitui pano de fundo a ser mencionado para compreendermos a dificuldade de se definir uma política nacional de educação que tenha como norte a busca da garantia de padrões mínimos para cada cidadão. A ação do município na educação fundamental deu-se de forma a suprir a omissão do estado, mas deu-se em condições significativamente adversas. Os municípios chamados a desempenhar tal função são precisamente os mais pobres, notadamente os do Nordeste.

Por hora, basta mencionar que tal diferenciação nacional impossibilitou, por ocasião da constituinte de $87 / 88$, qualquer política de distribuição de competências que superasse tais contradições históricas, fazendo com que o texto aprovado comportasse grande variedade de arranjos administrativos. (OLIVEIRA, 1997)

Apenas com a aprovação da Emenda Constitucional n. ${ }^{\circ}$ 14, de 1996, a distribuição de competências passou a ser mais clara, ainda que comportando acentuado grau de diferenciação.

A redação original do Artigo 211 da Constituição Federal, que estabelecia a distribuição de competências em termos de educação era a seguinte: 
Art. 211. A União, os Estados, o Distrito Federal e os Municípios organizarão em regime de colaboração seus sistemas de ensino.

$\S 1 .^{\circ}$ A União organizará e financiará o sistema federal de ensino e o dos Territórios, e prestará assistência técnica e financeira aos Estados, ao Distrito Federal e aos Municípios para o desenvolvimento de seus sistemas de ensino e o atendimento prioritário à escolaridade obrigatória.

$\S 2 .^{\circ}$ Os Municípios atuarão prioritariamente no ensino fundamental e pré-escolar.

Com o texto alterado, o Artigo 211 passou a vigir com a seguinte redação:

$\S 1^{\circ}$ A união organizará o sistema federal de ensino e o dos Territórios, financiará as instituições de ensino públicas federais e exercerá, em matéria educacional, função redistributiva e supletiva, de forma a garantir equalização de oportunidades educacionais e padrão mínimo de qualidade do ensino mediante assistência técnica e financeira aos estados, ao Distrito Federal e aos Municípios.

$\S 2^{\circ}$ Os Municípios atuarão prioritariamente no ensino fundamental e na educação infantil.

$\S 3^{\circ}$ Os Estados e o Distrito Federal atuarão prioritariamente no ensino fundamental e médio.

$\S 4^{\circ} \mathrm{Na}$ organização de seus sistemas de ensino, os Estados e os Municípios definirão formas de colaboração, de modo a assegurar a universalização do ensino obrigatório.

Ainda que o Ensino Fundamental permaneça como competência concorrente $^{1}$ de estados e municípios, a nova redação restringe apenas a estes dois níveis da federação a obrigação do atendimento à demanda, desobrigando a União de sua oferta direta, diminuindo a responsabilidade desta na contribuição financeira para com estados e municípios.

1 José Cretella Junior entende por competência concorrente à “...possibilidade jurídica de várias pessoas jurídicas políticas poderem legislar sobre determinada matéria. A Constituição Federal é que irá determinar se pessoas jurídicas políticas, que não a União, podem legislar, editando leis (a) ora suprindo a ausência de normas federais sobre determinada matéria, (b) ora adicionando pormenores à regra federal básica editada." (CRETELLA JUNIOR, 1991, p. 1598) 
Entretanto, previsões de "equalização de oportunidades educacionais e padrão mínimo de qualidade de ensino mediante assistência técnica e financeira aos estados, ao Distrito Federal e aos municípios" mantém a responsabilidade da União na redução das desigualdades educacionais, reafirmando-se sua função equalizadora. Dessa forma, a legislação vigente obriga a União a atuar para reduzir as desigualdades regionais em educação. Neste trabalho, analisa-se a ação da União com vistas a reduzir estas desigualdades por meio do Fundef e os limites de tal ação.

A maior dificuldade para implementar uma política decidida e homogênea de redução das desigualdades regionais é a diferença de responsabilidades efetivas para com o Ensino Fundamental e as demais etapas da Educação Básica, por parte das diferentes esferas da administração pública. As responsabilidades de estados e municípios variam muito de estado para estado.

Apenas a título exemplificador, observe-se os dados apresentados na tabela 1, acerca da distribuição da matrícula no Ensino Fundamental por dependência administrativa, no período 1975-2002.

TABELA 1 - BRASIL. ENSINO FUNDAMENTAL REGULAR - MATRÍCULA INICIAL 1975-2002

\begin{tabular}{c|r|r|r|r|r|r|r|r|r|r|c}
\hline \multicolumn{10}{c}{ Matrícula por Dependência Administrativa } \\
\hline Ano & \multicolumn{1}{l|}{ Total } & Federal & $\%$ & Estadual & $\%$ & \multicolumn{1}{l}{ Municipal } & $\%$ & Particular & $\%$ & Pop.7-14 anos & Mb \\
\hline 1975 & 19.549 .249 & 122.471 & 0,6 & 10.956 .560 & 56,0 & 5.948 .119 & 30,4 & 2.522 .099 & 12,9 & $*$ & \\
\hline 1980 & 22.598 .254 & 169.336 & 0,7 & 11.928 .315 & 52,8 & 7.602 .527 & 33,6 & 2.898 .074 & 12,8 & 22.981 .805 & 98 \\
\hline 1985 & 24.769 .359 & 116.848 & 0,5 & 14.178 .371 & 57,2 & 7.480 .433 & 30,2 & 2.989 .266 & 12,1 & 24.251 .162 & 102 \\
\hline 1989 & 27.557 .542 & 140.983 & 0,5 & 15.755 .120 & 57,2 & 8.218 .455 & 29,8 & 3.442 .984 & 12,5 & 27.509 .374 & 100 \\
\hline 1991 & 29.203 .724 & 95.536 & 0,3 & 16.716 .816 & 57,2 & 8.773 .360 & 30,0 & 3.618 .012 & 12,4 & 27.611 .580 & 105 \\
\hline 1996 & 33.131 .270 & 33.564 & 0,1 & 18.468 .772 & 55,7 & 10.921 .037 & 33,0 & 3.707 .897 & 11,2 & 28.525 .815 & 116 \\
\hline 1997 & 34.229 .388 & 30.569 & 0,1 & 18.098 .544 & 52,9 & 12.436 .528 & 36,3 & 3.663 .747 & 10,7 & 29.108 .003 & 116 \\
\hline 1998 & 35.792 .554 & 29.181 & 0,1 & 17.266 .355 & 48,2 & 15.113 .669 & 42,2 & 3.383 .349 & 9,5 & 26.400 .307 & 135 \\
\hline 1999 & 36.059 .742 & 28.571 & 0,1 & 16.589 .455 & 46,4 & 16.164 .369 & 44,5 & 3.377 .347 & 9,0 & 25.105 .782 & 143 \\
\hline 2000 & 35.717 .948 & 27.810 & 0,1 & 15.806 .726 & 44,3 & 16.694 .171 & 46,7 & 3.189 .241 & 8,9 & 27.124 .709 & 131 \\
\hline 2001 & 35.298 .089 & 27.416 & 0,1 & 14.917 .534 & 42,3 & 17.144 .853 .74 & 48,6 & 3.208 .286 & 9,1 & 26.820 .818 & 132 \\
\hline 2002 & 35.150 .362 & 26.422 & 0,1 & 14.236 .020 & 40,5 & 17.653 .1435 & 50,2 & 3.234 .777 & 9,2 & 27.040 .644 & 130 \\
\hline
\end{tabular}

FONTE: MEC-INEP/SEEC; IBGE.

* Não dispomos de dados da PNAD para o ano, pois em 1975 foi realizada em seu lugar o Estudo Nacional da Despesa Familiar (Endef).

Como se pode observar, por ocasião da aprovação do Texto Constitucional, a responsabilidade dos municípios para com a Educação Fundamental era acentuadamente menor que a dos estados. Além de muito diferenciada por região, em geral, com acentuada estadualização, particularmente no Sudeste, cujos números, pelas suas dimensões, impactam grandemente os totais nacionais. 
Essa distribuição foi significativamente alterada nos últimos anos, de modo a se ter um maior atendimento por parte das redes municipais, tornando-se, a partir de 2000, a principal provedora do Ensino Fundamental. A partir de 2002, as redes municipais passaram a atender a mais de $50 \%$ do total das matrículas. Tal alteração deveu-se a um aprofundamento dos percentuais de atendimento municipal em todas as regiões e, particularmente, a um aumento substantivo do atendimento por parte das redes municipais no Sudeste, notadamente nos estados de São Paulo e Minas Gerais, os mais estadualizados em meados da década passada. ${ }^{2}$ Tais alterações devem-se a um conjunto de políticas que contribuíram para a municipalização implementadas ao longo dos anos 90 e, particularmente, ao Fundef.

Na Tabela 2, pode-se observar a participação relativa das redes estaduais por região no total das matrículas no Ensino Fundamental, incluindo a rede privada, no período 1996-2002.

TABELA 2 - PERCENTUAL DE MATRICULADOS NO ENSINO FUNDAMENTAL ESTADUAL EM RELAÇÃO AO TOTAL DAS MATRÍCULAS

\begin{tabular}{c|c|c|c|c}
\hline & 1996 & 2000 & 2001 & 2002 \\
\hline Brasil & 55,74 & 44,25 & 42,26 & 40,50 \\
\hline Norte & 61,34 & 42,96 & 41,22 & 39,48 \\
\hline Nordeste & 39,58 & 31,72 & 30,03 & 28,20 \\
\hline Sudeste & 66,66 & 52,19 & 49,69 & 47,71 \\
\hline Sul & 54,60 & 49,86 & 49,03 & 47,76 \\
\hline Centro-Oeste & 62,91 & 57,24 & 54,78 & 53,25 \\
\hline
\end{tabular}

O percentual de atendimento das redes estaduais diminuiu em todas as regiões, conhecendo decréscimos mais significativos na região Sudeste (18,95\% de diminuição). Do total de 3.222.579 vagas a menos, ofertadas pelas redes estaduais no período, $2.337 .729(66,7 \%)$ foram reduzidas nos estados da região Sudeste.

Se tomarmos as variações de matrícula por estado, no período 19962002, pode-se observar, na tabela 3, a amplitude do impacto do processo de municipalização.

2 Excetuando-se os antigos territórios federais de Roraima e Amapá (tabela 3). 
OLIVEIRA, R. P. de. Uma dimensão avaliativa do Fundef:...

TABELA 3 - BRASIL - PERCENTUAL DE MATRÍCULAS NAS REDES ESTADUAIS NOS ANOS DE 1996-2002

\begin{tabular}{|c|c|c|c|}
\hline & 1996 & 2000 & \% Diferença \\
\hline Brasil & 55,74 & 40,50 & 15,24 \\
\hline Norte & 61,34 & 39,48 & 21,86 \\
\hline Rondônia & 61,11 & 49,70 & 11,40 \\
\hline Acre & 63,25 & 60,04 & 3,21 \\
\hline Amazonas & 60,35 & 46,00 & 14,35 \\
\hline Roraima & 93,72 & 84,65 & 9,07 \\
\hline Pará & 57,56 & 25,24 & 32,32 \\
\hline Amapá & 80,38 & 71,91 & 8,47 \\
\hline Tocantins & 66,08 & 54,42 & 11,66 \\
\hline Nordeste & 39,58 & 28,20 & 11,39 \\
\hline Maranhão & 31,34 & 22,87 & 8,47 \\
\hline Piauí & 39,50 & 28,59 & 10,91 \\
\hline Ceará & 32,07 & 17,43 & 14,63 \\
\hline R. G. do Norte & 45,18 & 37,44 & 7,74 \\
\hline Paraíba & 42,72 & 34,85 & 7,87 \\
\hline Pernambuco & 41,86 & 31,29 & 10,56 \\
\hline Alagoas & 29,08 & 23,85 & 5,23 \\
\hline Sergipe & 48,54 & 38,01 & 10,53 \\
\hline Bahia & 45,33 & 30,98 & 14,35 \\
\hline Sudeste & 66,66 & 47,71 & 18,95 \\
\hline Minas Gerais & 70,66 & 51,41 & 19,25 \\
\hline Espírito Santo & 65,24 & 46,09 & 19,15 \\
\hline Rio de Janeiro & 28,15 & 25,61 & 2,54 \\
\hline São Paulo & 77,27 & 54,81 & 22,46 \\
\hline Sul & 54,60 & 47,76 & 6,85 \\
\hline Paraná & 49,25 & 44,92 & 4,34 \\
\hline Santa Catarina & 64,53 & 49,84 & 14,69 \\
\hline R. G. do Sul & 54,63 & 49,39 & 5,24 \\
\hline Centro-Oeste & 62,91 & 53,25 & 9,66 \\
\hline M.G. do Sul & 53,93 & 47,89 & 6,05 \\
\hline Mato Grosso & 58,68 & 46,29 & 12,38 \\
\hline Goiás & 61,36 & 50,09 & 11,27 \\
\hline Distrito Federal & 82,31 & 80,68 & 1,64 \\
\hline
\end{tabular}


Por meio desses dados observa-se que em todos os estados diminuiu o percentual de atendimento do Ensino Fundamental por parte das redes estaduais, com quedas acentuadíssimas em estados como o Pará $(32,32 \%)$, São Paulo (22,46\%), Minas Gerais (19,25\%) e Espírito Santo (19,15\%). São Paulo e Minas, os dois mais populosos, são os responsáveis principais pela mudança no perfil nacional.

Essas alterações no perfil do atendimento, que se mantém nos anos de 2002 e 2003 fazem com que o papel do município no atendimento ao Ensino Fundamental seja significativamente ampliado. Ao mesmo tempo, o perfil nacional de atendimento entre estados e municípios tende a se homogeneizar. Apesar de tal processo ainda necessitar um balanço mais acurado, há um aspecto que já pode ser enfatizado como positivo, a possibilidade de formulação de políticas nacionais mais uniformes entre as regiões.

Dada essa alteração, impulsionada pelo conjunto de políticas implementadas na última década, coloca-se com clareza a necessidade de formulação de políticas educacionais que enfrentem a desigualdade regional, questão da qual tratarei a seguir, iniciando pelos diferenciais estaduais de gasto/aluno observados após a implantação do Fundef.

\section{A dimensão nacional: o valor do gasto/aluno/ano do Fundef}

A primeira das questões relativas à equalização diz respeito ao cumprimento da Lei n. ${ }^{\circ}$ 9.424/96, que regulamentou o Fundef. Enunciando rapidamente: há uma dimensão nacional do Fundef. Grosso modo, há a transferência de impostos, tanto da União para os estados, quanto dos estados para os municípios. Segundo a Lei n. 9.424/96, contingencia-se 15\% de alguns dos impostos transferidos de uma esfera a outra, ${ }^{3}$ que têm de ser aplicados no Ensino Fundamental. Para se chegar ao gasto médio nacional por aluno, deve-se dividir $15 \%$ da receita de impostos pelo número de alunos matriculados no Ensino Fundamental. Com isso, obtém-se um nú-

3 Os impostos sobre os quais incide o Fundef são o IPI e o IR, que fornecem recursos para os Fundos de Participação de Estados e Municípios (FPE e FPM), o ICMS e a desoneração do ICMS (LC-87, conhecida como Lei Kandir) e do IPI-exportação, que incidem sobre produtos exportados. 
mero referência, que seria uma média nacional de gasto por aluno, no Ensino Fundamental. Isso na introdução do fundo. Nos anos seguintes, devem ser estimados dois outros fatores: um no numerador, que seria a perspectiva de crescimento da receita, e uma expectativa do aumento da matrícula, cuja razão comporia o gasto médio nacional por aluno. Qual é o papel da União? Ela faz esse cálculo e o presidente da república decreta o valor nacional. A partir daí, a operacionalização do Fundo passa para cada estado, com exceção dos casos de complementação da União, dos quais tratarei adiante.

No âmbito dos estados, do total de recursos disponíveis provenientes de transferências e de alguns impostos privativos dos mesmos, contingencia-se $15 \%$, a serem aplicados no Ensino Fundamental, e faz-se a divisão pelo número de alunos deste nível de ensino e se obtém a média do estadual. Esta média é o potencial do estado. Na hipótese de o gasto ser menor do que o valor estabelecido nacionalmente, a União complementaria os valores do fundo até que este atingisse a média nacional. Dessa forma, a média nacional se transformaria, em termos do gasto por aluno, em um mínimo a ser observado.

Todos os estados deveriam gastar pelo menos a média nacional, contanto para tal com a suplementação da União. Aí reside a controvérsia. Em 97, a União trabalhava com a idéia de que o gasto médio nacional seria de $\mathrm{R} \$ 300,00$, mas o Fundo só começa a vigir a partir de 98. No segundo semestre de 1997, houve uma experiência de implantação no Pará e outra no Ceará, neste último, apenas para alguns municípios. Apenas a partir de 98, é que o Fundo vigorou para o Brasil todo. Desde então, o governo federal subestimou o valor da média nacional. O que acontece? Se a média nacional fosse maior, o montante a ser complementado pela União para os estados seria maior. Quando diminui essa média, tanto o número de estados abrangidos pela suplementação federal é menor, quanto o montante da complementação. Para não nos determos, por enquanto, no debate sobre a fidedignidade das fontes de informação, tomemos documentos de entidades nacionais representando setores do poder executivo: a União Nacional dos Dirigentes Municipais de Educação - Undime, e o Conselho dos Secretários de Estado - Consed. Estas organizações contestaram os números do governo federal (gestão FHC) nesse particular. Durante a campanha eleitoral de 2002, um dos pontos programáticos do presidente eleito era "restaurar os valores do gasto aluno do Fundef estabelecido pela Lei."

Segundo as entidades mencionadas, em 1998, o valor fixado pela União para o gasto/aluno/ano/nacional, de $\mathrm{R} \$ 315,00$, estaria abaixo do estipulado na lei. A Undime trabalhava com um valor de $\mathrm{R} \$ 419,00$, número reconhe- 
cido também pela CPI do Fundef, da Câmara dos Deputados, portanto R\$ 104,00 per capita a mais do que o estabelecido pelo governo federal. O Consed trabalhava com $\mathrm{R} \$ 433,00$ (CONSED, 1999-2000-2001, p. 24-30). Em 1998, o governo federal complementou, em valores de 98, R\$ 486 milhões para o Fundef. Se a média nacional de gasto fosse de R \$419,00 esse valor seria de aproximadamente $\mathrm{R} \$ 1.500$ milhões e, evidentemente, abrangeria mais estados. Esse é o primeiro ponto que valeria a pena fixar.

Já se têm diversos pronunciamentos ratificando o entendimento de que o governo federal não vem cumprindo o que a Lei n. 9.424/96 estabelece, inclusive na CPI da Câmara, subcomissão que investigou o caso, representação do Ministério Público junto ao Supremo etc. O governo federal não cumpria e ainda não cumpre a lei de sua própria iniciativa. O que é mais constrangedor é que o Fundef foi a grande política do governo Fernando Henrique no que diz respeito à educação.

A partir de 2000, diferenciou-se o gasto de $1^{\mathrm{a}}$ a $4^{\mathrm{a}}$ séries e de $5^{\mathrm{a}}$ a $8^{\mathrm{a}}$. Era uma das possibilidades contempladas na Lei n. 9424/96. Nesse ano, o valor oficial foi de $\mathrm{R} \$ 333,00$ por aluno de $1^{\mathrm{a}}$ a $4^{\mathrm{a}}$ séries e $\mathrm{R} \$ 349,65$ para $5^{\mathrm{a}}$ a $8^{\mathrm{a}}$, enquanto o Consed trabalhava com valores de $\mathrm{R} \$ 494,00$ para $1^{\mathrm{a}}$ a $4^{\mathrm{a}}$ e de $\mathrm{R} \$ 519,00$ para $5^{\mathrm{a}}$ a $8^{\mathrm{a}}$ séries, o que implicaria em um montante de complementação e de recursos do governo federal muito maior. $\mathrm{O}$ agravante é que o governo do PT, apesar de promessa em contrário, não alterou tal prática, reajustando tais valores em torno de apenas $7 \%$, ou seja, mantendo a distância entre o estabelecido em lei e o decretado.

TABELA 4 - FUNDEF - EVOLUÇÃO DO VALOR MÍNIMO ANUAL POR ALUNO: LEI 9424/96, VALOR OFICIAL DECRETADO E VALOR OFICIAL DEFLACIONADO PELO IGPDI - 1997/2003

\begin{tabular}{l|l|l|l|l|l|l|l|l}
\hline Fonte/ano & & 1997 & 1998 & 1999 & 2000 & 2001 & 2002 & 2003 \\
\hline \multirow{2}{*}{$\begin{array}{l}\text { Lei n. } \\
9424 / 96\end{array}$} & $1^{\mathrm{a}} \cdot / 4^{\mathrm{a}}$. & 300,00 & 418,77 & 418,56 & 455,23 & 522,13 & 613,67 & 733,80 \\
\cline { 2 - 9 } & $5^{\mathrm{a}} . / 8^{\mathrm{a}}$. & $*$ & $*$ & $*$ & 478,00 & 548,23 & 644,35 & 770,50 \\
\hline \multirow{2}{*}{ Oficial } & $1^{\mathrm{a}} \cdot / 4^{\mathrm{a}}$. & 300,00 & 315,00 & 315,00 & 333,00 & 363,00 & 418,00 & 446,00 \\
\cline { 2 - 9 } & $5^{\mathrm{a}} \cdot / 8^{\mathrm{a}}$. & $*$ & $*$ & $*$ & 349,65 & 381,15 & 438,90 & 468,30 \\
\hline \multirow{2}{*}{$\begin{array}{l}\text { Deflacionados } \\
\text { (maio/03) }\end{array}$} & $1^{\mathrm{a}} \cdot / 4^{\mathrm{a}}$. & 614,82 & 618,34 & 564,35 & 519,90 & 513,80 & 529,31 & 456,83 \\
\cline { 2 - 8 } & $5^{\mathrm{a}} \cdot / 8^{\mathrm{a}}$. & $*$ & $*$ & $*$ & 545,90 & 539,49 & 555,78 & 479,67 \\
\hline
\end{tabular}

FONTE: UNDIME E STN/MF, IGPDI-FGV

NOTA: * Os valores de 1\%/4 séries e 5/8a séries e Educação Especial não eram diferenciados nestes anos. Obs.: Os valores de de 5ª $/ 8^{\mathrm{a}}$ séries e Educação Especial são iguais. 
Por esses dados, é possível perceber o quanto o governo federal se distancia da Lei. Tomando os valores oficiais em valores reais, deflacionados pelo IGPDI da Fundação Getúlio Vargas, para maio 2003, apresentados na tabela 4, pode-se ter uma idéia também da dinâmica do gasto em educação no período e verificar que os valores decretados têm diminuído, em termos reais, ao longo do tempo, com pequena inflexão em 2002, apesar de seu crescimento nominal. Esse resultado indica que o compromisso da União com o Ensino Fundamental tem diminuído ao longo do tempo. ${ }^{5}$

$\mathrm{Na}$ medida em que a União não cumpre o seu papel complementar no Fundo, ela aprofunda as desigualdades regionais, contrariamente a um dos objetivos declarados do Fundef. Apesar de se ter uma possibilidade de diminuição da desigualdade internamente a cada estado, a omissão do governo federal, neste caso, é amplificadora das desigualdades regionais. São Paulo, por exemplo, já apresenta um gasto por aluno superior a $\mathrm{R} \$ 1000,00$, enquanto que os estados que estão recebendo complementação (Pará, Piauí, Maranhão e Bahia) ficarem próximos do valor mínimo nacional.

Se tomarmos como referência a idéia de um estado que garanta um padrão mínimo de qualidade para todos os cidadãos, ao pensarmos a desigualdade nacional, verificamos que no Brasil a tensão entre federalismo e desigualdade em educação se acentua, estando a exigir ações políticas que rompam com um padrão historicamente estabelecido e transcendam os limites estaduais em que o Fundef e, mesmo a alternativa do Fundeb, se circunscrevem.

\section{REFERÊNCIAS}

ALMEIDA, M. H. T. Federalismo e Políticas Sociais. In: AFFONSO, R. B. A.; SILVA, P. L. B. Federalismo no Brasil. São Paulo: Fundap, 1996.

BRASIL. Lei 9.424, de 24 de dezembro de 1996. Dispõe sobre o Fundo de Manutenção e Desenvolvimento do Ensino Fundamental e de Valorização do Magistério. Diário Oficial da União, Brasília, dez. 1996.

5 Sem mencionar o fato de que o montante da complementação da União aos estados que não atingem os valores mínimos do Fundef é menor que a quota federal do salárioeducação, recurso que já iria para o Ensino Fundamental de toda forma. 
CONSED. Relatório da Gestão 1999-2000 - O Cenário Econômico: os impactos do ajuste fiscal na educação, Brasília: Consed, 2001.

CRETElla JUNIOR, J. Comentários à Constituição Brasileira de 1988. 2. ed. São Paulo: Forense Universitária, 1991. v. 3, arts. 18-22.

SILVA, B. (Coord.). Dicionário de Ciências Sociais da Fundação Getúlio Vargas. Instituto de Documentação. 2. ed. Rio de Janeiro: Ed. Fundação Getúlio Vargas, 1987.

MARShAlL, T. H. Política Social. Tradução de Meton P. Gadelha. Rio de Janeiro: Zahar, 1967.

OLIVEIRA, R. P. A Municipalização do Ensino no Brasil. In: OLIVEIRA, D. A. Gestão Democrática da Educação. Petrópolis: Vozes, 1997. p. 174-198.

Texto recebido em 10 ago. 2003 Texto aprovado em 03 out. 2003 